\title{
Diagnostic yield of allergy testing in Pediatric Eosinophilic Esophagitis: a 10 year experience at a tertiary care centre
}

Perri R Tutelman ${ }^{1 *}$, Jason Ohayon ${ }^{2}$, Jefferson Terry ${ }^{3}$, Mary E Sherlock ${ }^{1}$

From Canadian Society of Allergy and Clinical Immunology Annual Scientific Meeting 2013

Toronto, Canada. 3-6 October 2013

\section{Background}

Eosinophilic Esophagitis (EoE) is a disease in children characterized by esophageal dysfunction and eosinophilic infiltration [1]. Patients frequently present with an atopic history; therefore, allergy testing by both skin prick and food patch testing are often performed. However, the utility of allergy testing remains unclear [1,3]. Treatment with topical corticosteroids may be needed for clinical and histologic improvement if allergic triggers are not identified [1,2]. However, the natural history of EoE suggests that this condition is chronic and may recur when corticosteroids are withdrawn [2]. Therefore, treatment with dietary/aeroallergen avoidance is preferable to reduce the need for oral corticosteroids, while preventing exacerbation of EoE [3]. This study aims to describe the atopic characteristics of a pediatric cohort with EoE over a 10 year period at a tertiary care center.

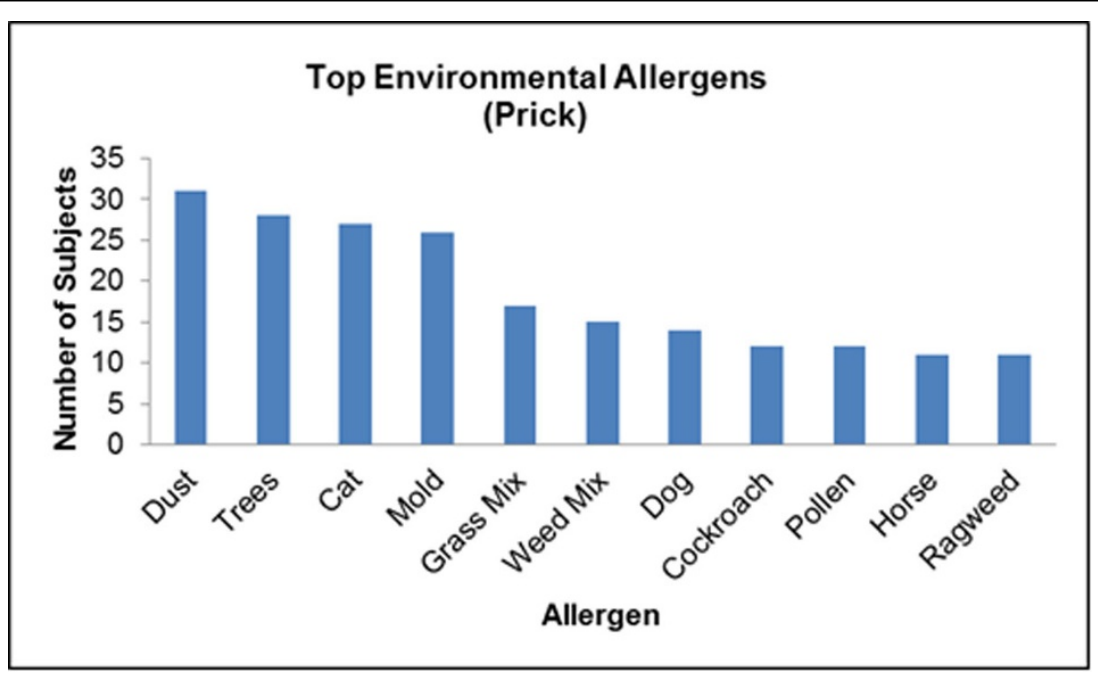

Figure $1(N=69)$ underwent skin prick testing

\footnotetext{
* Correspondence: tutelmp@mcmaster.ca

'Pediatric Gastroenterology and Nutrition, McMaster Children's Hospital,

McMaster University, Hamilton, Ontario, Canada

Full list of author information is available at the end of the article
}

(c) 2014 Tutelman et al; licensee BioMed Central Ltd. This is an Open Access article distributed under the terms of the Creative Commons Attribution License (http://creativecommons.org/licenses/by/2.0), which permits unrestricted use, distribution, and 


\section{Methods}

All children ( $<18$ years) who had esophagogastroduodenoscopy with biopsy proven EoE (15+ eosinophils per high power field) at McMaster Children's Hospital between January 2003 and December 2012 were identified and their medical records reviewed. Data pertaining to patient demographics, symptoms at diagnosis, atopic history, endoscopic and histologic findings, results of allergy testing (skin prick, patch and immunoCAP) and treatment outcomes were extracted.

\section{Results}

A total of 96 cases were identified. The median age at diagnosis was 13.2 years $(\mathrm{IQR}=8.6-15.7)$, and 72 of the identified cases were male $(74.2 \%)$. Seventy-four of $91(81 \%)$ and 62 of 79 (78\%) patients with data available reported a history of personal and family atopy, respectively. Six patients (7\%) had a first degree family member diagnosed with EoE. Patients who reported a history of food allergy were significantly more likely to present with a food bolus impaction at diagnosis $(\mathrm{p}=0.035, \mathrm{OR}=3.056)$. Sixty-nine patients underwent allergy testing as part of a standard EoE workup, of which, 60 (87.0\%) had a positive test result. Ten $(14.5 \%)$ patients who had identifiable allergies were positive only to environmental allergens. The top identified food and environmental allergens were recorded by allergy test type (Figs 1, 2, 3, 4).

\section{Conclusions}

Pediatric EoE is considered to be an allergic disease with both environmental and food allergen triggers in many patients. A majority of patients present with a history of

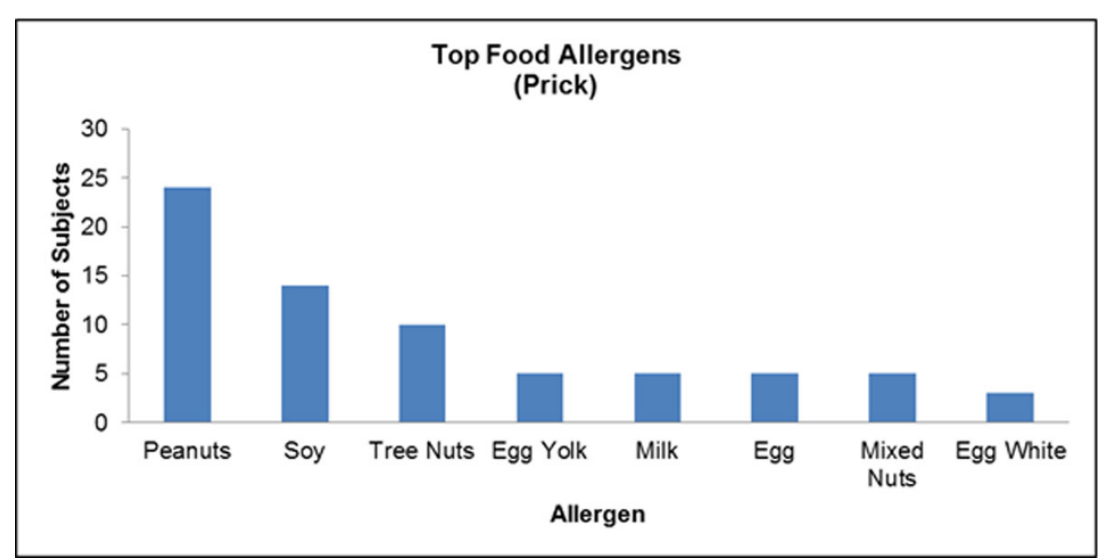

Figure $2 \mathrm{~N}=69$ underwent skin prick testing

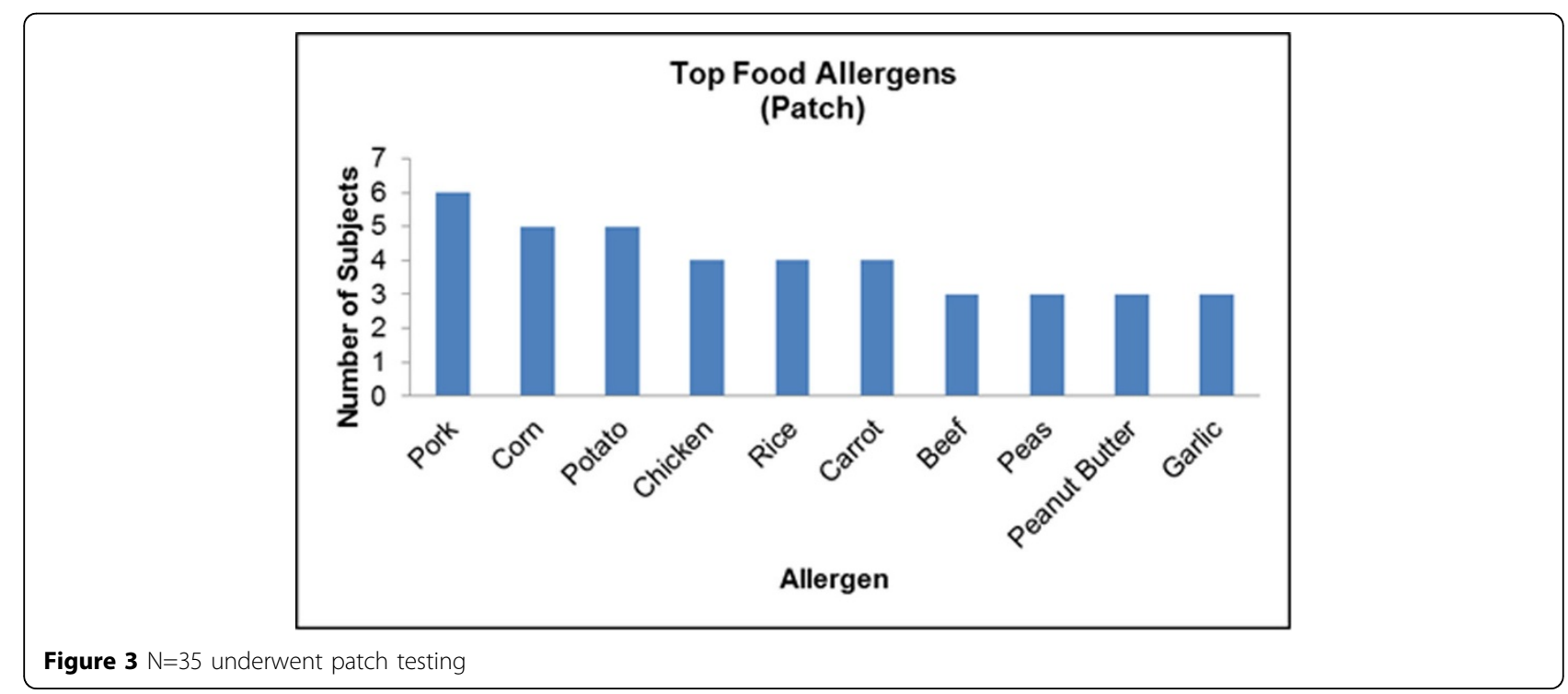




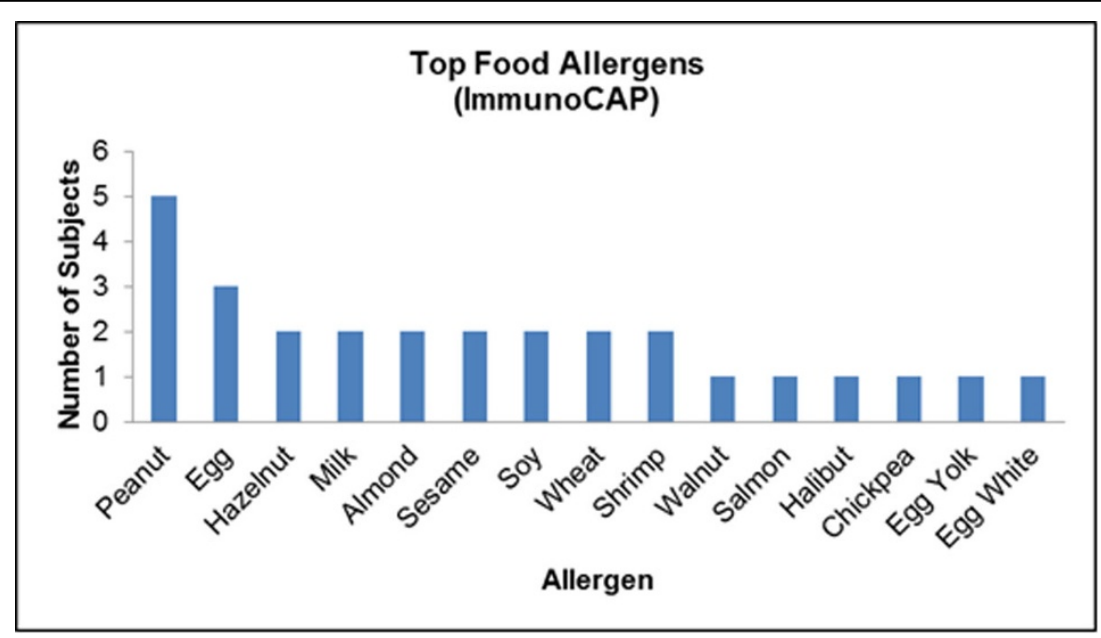

Figure $4 \mathrm{~N}=14$ underwent ImmunoCAP testing.

atopy and show positive allergy test results to both foods and aeroallergens. Both environmental and food allergen elimination should be considered a part of a therapeutic program. Identification of offending allergens by allergy skin and patch testing can be an important factor in guiding clinical decision making.

\section{Authors' details}

${ }^{1}$ Pediatric Gastroenterology and Nutrition, McMaster Children's Hospital, McMaster University, Hamilton, Ontario, Canada. ${ }^{2}$ Department of Pediatrics, McMaster Children's Hospital, McMaster University, Hamilton, Ontario, Canada. ${ }^{3}$ Department of Pathology and Molecular Medicine, McMaster Children's Hospital, McMaster University, Hamilton, Ontario, Canada.

Published: 3 March 2014

\section{References}

1. Liacouras CA, Furuta GT, Hirano I, Atkins D, Attwood SE, Bonis PA, et al: Eosinophilic esophagitis: updated consensus recommendations for children and adults. J Allergy Clin Immunol 2011, 128:3-20.

2. Helou EF, Simonson J, Arora AS: 3-Yr-Follow-Up of Topical Corticosteroid Treatment for Eosinophilic Esophagitis in Adults. Am J Gastroenterol 2008, 103:2194-2199.

3. Henderson CJ, Abonia JP, King EC, Putnam PE, Collins MH, Franciosi JP, et al: Comparative dietary therapy effectiveness in remission of pediatric eosinophilic esophagitis. J Allergy Clin Immunol 2012, 129:1570-1578.

doi:10.1186/1710-1492-10-S1-A28

Cite this article as: Tutelman et al:: Diagnostic yield of allergy testing in Pediatric Eosinophilic Esophagitis: a 10 year experience at a tertiary care centre. Allergy, Asthma \& Clinical Immunology 2014 10(Suppl 1):A28.

\section{Submit your next manuscript to BioMed Central} and take full advantage of:

- Convenient online submission

- Thorough peer review

- No space constraints or color figure charges

- Immediate publication on acceptance

- Inclusion in PubMed, CAS, Scopus and Google Scholar

- Research which is freely available for redistribution

Submit your manuscript at www.biomedcentral.com/submit 